\title{
PERCEPÇÃO DOS ALUNOS DO CURSO DE ODONTOLOGIA DE UMA UNIVERSIDADE BRASILEIRA EM RELAÇÃO À IMPORTÂNCIA DA DISCIPLINA DE BIOQUÍMICA NA SUA PROFISSÃO.
}

\author{
Rodrigo Cardoso de Oliveira*1, Flávia Godoy Iano², Thelma Lopes da Silva ${ }^{3}$ e Marília \\ Afonso Rabelo Buzalaf ${ }^{4}$ \\ ${ }^{1}$ Professor Doutor do Departamento de Ciências Biológicas/Bioquímica, FOB-USP \\ ${ }^{2}$ Farmacêutico-Bioquímico e técnico do laboratório de Ciências Biológicas/Bioquímica, FOB-USP \\ ${ }^{3}$ Doutorando do curso Biologia Funcional e Molecular, Instituto de Biologia, UNICAMP \\ ${ }^{4}$ Professor Associado do Departamento de Ciências Biológicas/Bioquímica, FOB-USP
}

\section{Resumo:}

O aprendizado de disciplinas de ciências básicas, no curso de graduação em Odontologia, é necessário e cada vez mais exigido para a formação de um profissional atento aos avanços tecnológicos na área da saúde. O objetivo deste trabalho foi avaliar a percepção dos alunos do primeiro ano do curso de Odontologia da Faculdade de Odontologia de BauruUSP, no ano de 2006, em relação à importância da disciplina de bioquímica na sua formação e atuação profissional. Foi proposto um questionário simples composto de duas questões de múltipla escolha sobre a disciplina de bioquímica, avaliando sua aplicabilidade e importância no cotidiano do cirurgião-dentista. Os alunos $(n=34)$ responderam às questões sem a necessidade de se identificarem, para que não sofressem inibição ou mesmo receio de qualquer comentário sobre respostas individuais. $O$ interesse pela bioquímica se mostrou elevado. A grande maioria dos alunos (88,23\% e $82,35 \%$ na primeira e segunda questão respectivamente) respondeu acreditar no uso prático do conteúdo da disciplina de bioquímica na formação e atuação profissional. Uma pequena parcela $(11,87 \%$ e $17,65 \%$ na primeira e segunda questão, respectivamente) respondeu não acreditar que o conteúdo da disciplina fosse importante e aplicável no cotidiano do profissional. Considerando que os alunos do primeiro ano do curso de odontologia precisão ser motivados a aprender conceitos básicos para aplicações futuras, podemos concluir que existem uma motivação e interesse pela bioquímica que devem ser, na medida do possível, mantidos pelos professores responsáveis.

\section{Abstract:}

The learning basic sciences discipline in the course of Dentistry is necessary and each time more demanded for the formation of professional in-line the technological advances in the field of health. The objective of this work was to evaluate the perception of the students of the first year of the course of Dentistry of the Faculdade de Odontologia de Bauru-USP, in the year of 2006, in relation to the importance of discipline of biochemistry on its formation and professional performance. A simple questionnaire composed of two multiple choice questions related to the discipline of biochemistry, was applied to the undergraduate first-year students evaluating its applicability and importance in the daily one of the dentist. The students $(n=34)$ answered to the questions without identifying themselves, so that they did not suffer any inhibition or even fear regarding the individual answers. The interest for the biochemistry was shown to be high. The great majority of the students $(88.23 \%$ and $82.35 \%$ for the first and the second questions, respectively) related to believe they would use the content of disciplines of biochemistry for their formation and professional performance. A small parcel $(11.87 \%$ and $17.65 \%$ in the first and the second questions, respectively) related not to believe that the content of the discipline was important and applicable in the daily professional life. Considering that the students of the first year of the dentistry course need to be motivated to learn basic concepts for future applications, we can conclude that there are motivation and interest for the discipline of biochemistry and these must be kept, whenever possible, by the responsible professors. 


\section{INTRODUÇÃO}

O ensino de disciplinas centradas em matérias básicas (histologia, anatomia, fisiologia, farmacologia, bioquímica e outras), no curso de graduação em odontologia, visa à formação integral de um profissional que terá o desafio de estabelecer uma conduta clínica de diagnóstico, tratamento e prognóstico ao seu paciente [1]. Em outras palavras: as disciplinas básicas, ministradas no início do curso de odontologia, têm por objetivo constituir uma formação sólida de conhecimentos aplicados no dia-adia do profissional clínico [2]. Tais conhecimentos sem uma aplicação ou uma função clara na vida do cirurgião-dentista não teria nenhum valor concreto [3]. Por isso, especificamente o ensino de bioquímica, tem sido uma preocupação de diversos docentes [4], tendo em vista que a citada disciplina é utilizada como uma ferramenta de diagnóstico e tratamento pelo clínico [5]. No entanto essa disciplina como também outras disciplinas básicas, apresenta certa rejeição por parte considerável dos alunos de odontologia, e mesmo de alguns professores de outras áreas [6]. Isso se deve em parte à idéia errônea de que seu conteúdo não teria uma aplicação prática ou mesmo que sua importância frente às disciplinas chamadas "clínicas" seria pequena ou mesmo nula [7].

Outro ponto para essa discussão seria que a importância dessas disciplinas (ciências básicas) pode muitas vezes ser eclipsada por motivos menores como a ansiedade do aluno em praticar situações clínicas apenas com treinamentos mecânicos e repetitivos, sem antes entender o contexto clínico do paciente. Essa ansiedade de "pular etapas" na aprendizagem pode levar o aluno, principalmente o de odontologia, a minimizar ou quase mesmo anular a bagagem de conhecimento de disciplinas básicas [8,9], inclusive a de bioquímica, levando-o a um prejuízo futuro em sua profissão.

Especialmente nessas duas últimas décadas, onde vimos as Ciências Biológicas darem enormes passos como o seqüenciamento completo do genoma humano [10], o surgimento da Engenharia de Tecidos, introduzido por Langer e Vacanti (1993) [11] concomitantemente com o uso de células-tronco $[6,12,13]$, trazendo à área de saúde, e consequentemente à Odontologia, o poder de usufruir de informações e técnicas não disponíveis anteriormente $[6,14,15]$. Assim, mais do que nunca, o aluno de Odontologia e futuro cirurgião-dentista deve ter em mente que o mercado de trabalho vai cobrar dele novas informações bem como confrontá-lo com novas situações, não vivenciadas anteriormente. Desse modo, a formação em disciplinas que dêem esse conhecimento se faz necessário. No entanto cabe saber se os alunos e professores têm essa consciência, uma vez que isso vai influenciá-los decisivamente no aprendizado dessa disciplina.

Portanto, se torna imperativo entender a percepção do aluno de graduação do curso de Odontologia do primeiro ano sobre sua perspectiva e interesse no uso dos conhecimentos de bioquímica para sua futura profissão, visando assim à adequação do conteúdo da disciplina, bem como da conduta pedagógica dos professores responsáveis.

\section{MATERIAL E MÉTODO}

Foi proposto um questionário simples composto de duas questões de múltipla escolha sobre a disciplina de bioquímica, avaliando sua aplicabilidade e importância no cotidiano do cirurgião-dentista (Esquema 1). Os questionários foram aplicados aos alunos do primeiro ano do curso de Odontologia da Faculdade de Odontologia de Bauru - Universidade de São Paulo, ao final do curso de bioquímica básica e bioquímica oral (junho de 2006 - primeiro semestre completo). Os alunos responderam às questões sem a necessidade de se identificarem, para que não sofressem inibição ou mesmo receio de qualquer comentário sobre respostas individuais, sendo o seu preenchimento feito de forma voluntária. No total, 34 alunos responderam o questionário. 


\section{Preparo do material}

Os questionários foram elaborados e posteriormente lidos por professores responsáveis pela disciplina e por dois colaboradores no preparo de aulas teóricas e práticas. As respostas foram avaliadas de forma subjetiva, indicando a opinião do aluno em relação a cada questão (Esquema 1 ).

\section{Esquema 1: Questionário aplicado aos alunos do curso de odontologia do primeiro ano do curso de graduação.}

1) Em sua opinião, o curso de bioquímica ministrado terá relevância na sua formação profissional?
a) Sim
b) Apenas em parte
c) Muito pouco
d) Nenhuma

2) O uso do conteúdo do curso de bioquímica parece ser importante no cotidiano clínico do cirurgião-dentista?
a) $\operatorname{Sim}$
b) Apenas alguns
c) Nenhum deles
d) Não tenho tempo suficiente de curso para responder

\section{RESULTADOS}

O interesse pela bioquímica se mostrou elevado. A grande maioria dos alunos (88,23\% e $82,35 \%$ na primeira e segunda questão, respectivamente) respondeu acreditar no uso prático do conteúdo da disciplina de bioquímica na formação (primeira questão) e atuação profissional (segunda questão). Uma pequena parcela $(11,87 \%$ e $17,65 \%$ na primeira e segunda questão, respectivamente) respondeu não acreditar que o conteúdo da disciplina fosse importante (primeira questão) e aplicável no cotidiano do profissional (segunda questão) (Gráficos 1 e 2). 


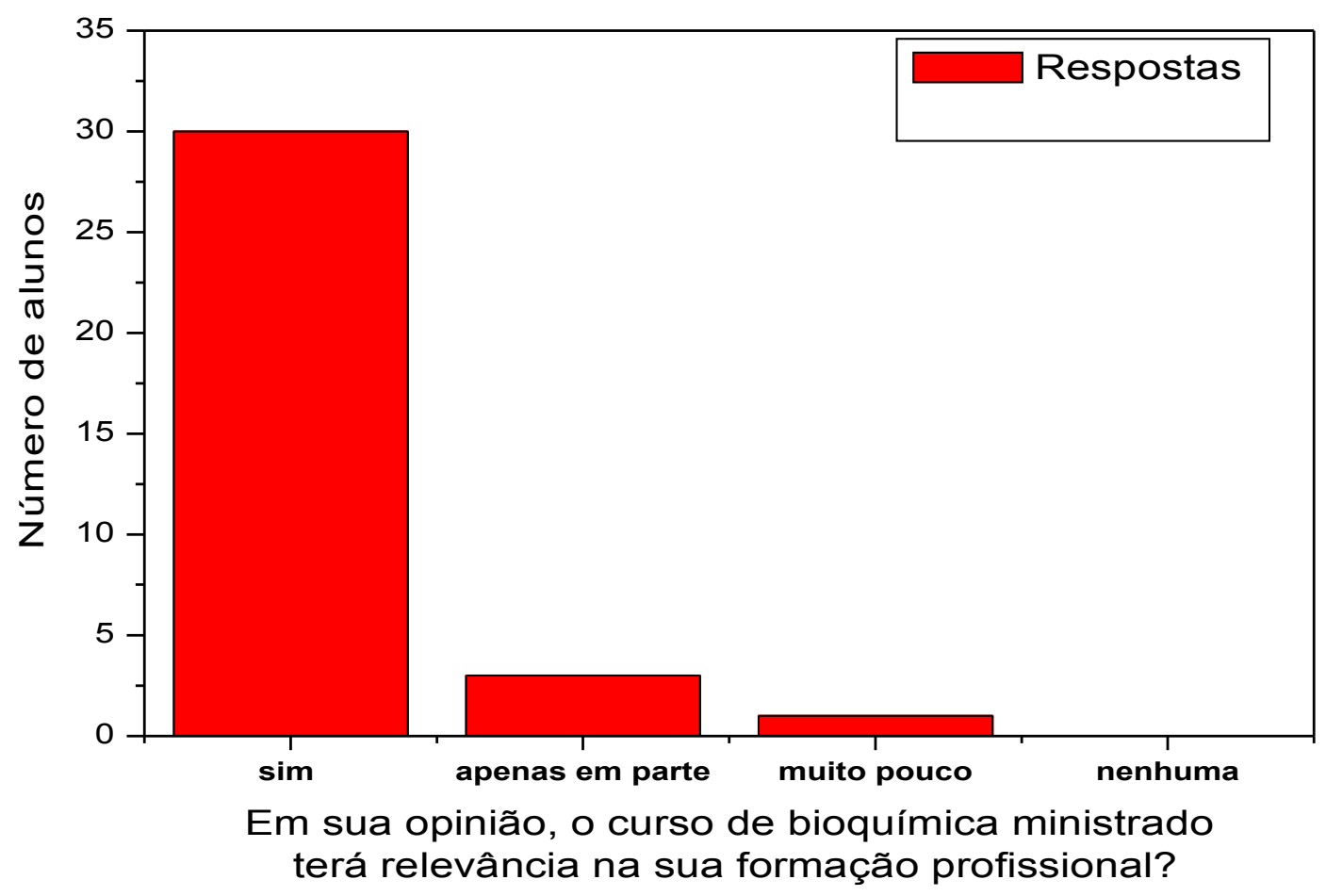

Gráfico 1: Número de respostas propostas para a questão 1. $n=34$.

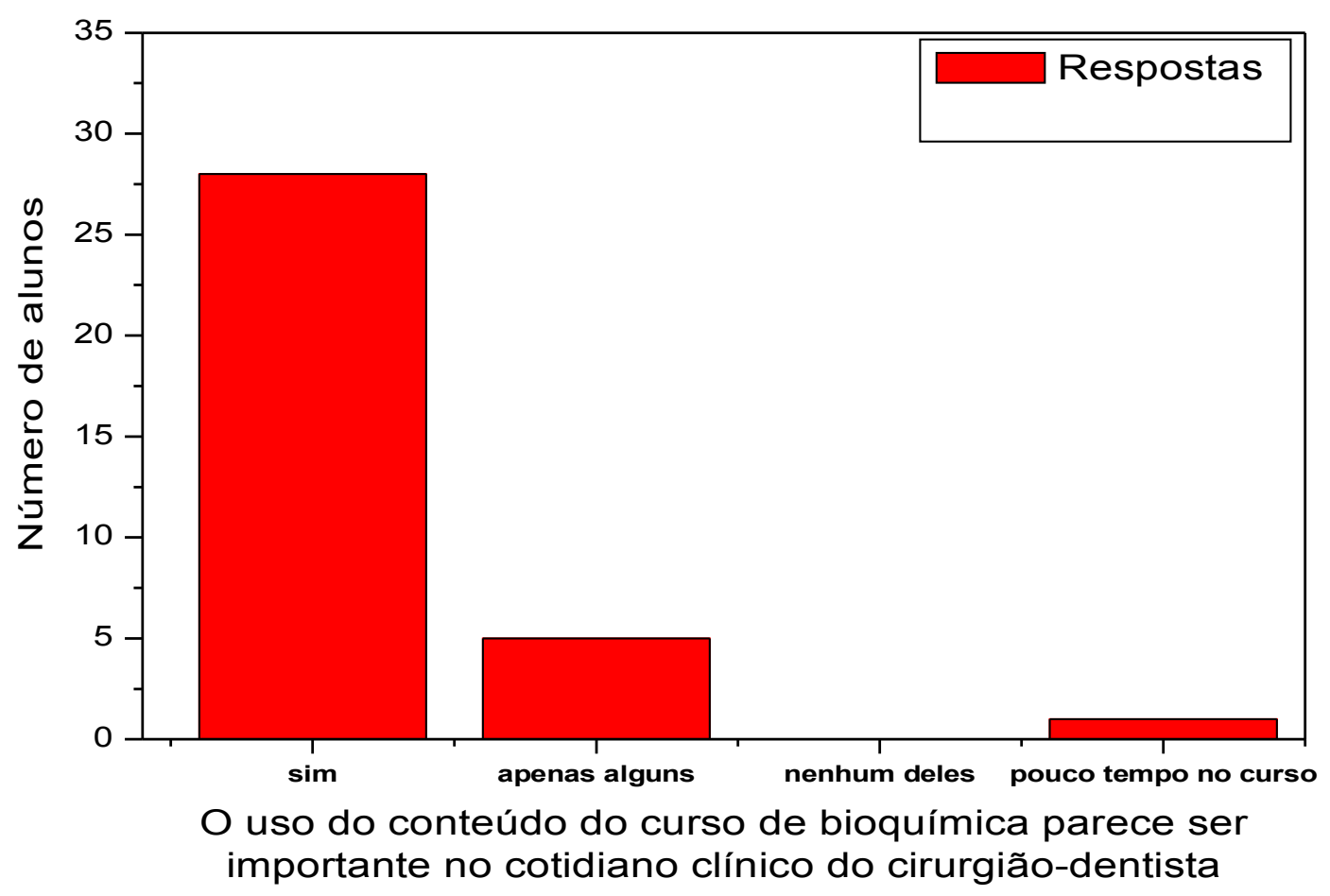

Gráfico 2: Número de respostas propostas para a questão 2. n=34. 


\section{DISCUSSÃO}

O perfil clássico do aluno ingressante no curso de Odontologia é descrito como um estudante que busca um curso que o apresente imediatamente a técnicas manuais sem um aprofundamento em conhecimento básico, sendo muito comum a idéia da profissão se resumir no conhecimento da anatomia dental [7]. A maioria dos alunos que ingressam na graduação em Odontologia no Brasil estão numa faixa etária de 1719 anos. Isso parece colaborar com um fenômeno interessante: uma ansiedade e impaciência no cumprimento de todas as etapas de formação e sustentação antes que esse aluno possa realizar seus atendimentos na clínica da Faculdade.

O presente trabalho sugere uma nova percepção do aluno de Odontologia, em relação a resultados antigos como descritos por Welker (1992) [7], onde era questionada a importância de disciplinas básicas, como por exemplo bioquímica. Talvez essa nova percepção e compreensão dos alunos se devam, em grande parte, à expectativa gerada por descobertas animadoras e extremamente divulgada pelas mídias e por publicações especializadas $[10,12]$. Avanços como a clonagem de mamíferos, Projeto Genoma Humano, engenharia de tecidos e uso de células-tronco têm despertado os alunos para as disciplinas básicas que seguiam geralmente num segundo plano $[6,13]$. Neste ponto, as disciplinas de cadeira básica ganharam um forte aliado no despertar do interesse do aluno para seu conteúdo.

Outro ponto a ser destacado, como descrito anteriormente por Baum (2003) [6], é o posicionamento dessas disciplinas em um segundo plano pelos próprios educadores em Odontologia, onde o mercado de trabalho teria uma influência exagerada e precipitada na formação de profissionais apenas com habilidades técnicas, mas sem uma formação crítica e auto-suficiente [6]. Essa segunda resistência também tem diminuído à medida que o avanço no campo da ciência tem ditado as normas do próprio mercado de trabalho e também, sugerido no presente trabalho, pela mudança de atitude dos novos estudantes que entram no curso de Odontologia.

O professor de disciplinas básicas tem que se valer de técnicas motivacionais e expor o mais claro possível a aplicação dos conhecimentos estudados na sua disciplina. Pode-se sugerir que o processo de motivação e convencimento da importância da disciplina básica na formação do profissional seja o ponto mais crítico para os alunos do primeiro ano do curso de Odontologia.

Especificamente no Brasil, como descrito nesse trabalho, temos uma sugestão de mudança do perfil do aluno ingressante no curso de Odontologia quanto à sua percepção sobre a importância e aplicabilidade da disciplina de bioquímica em sua profissão.

\section{CONCLUSÃO}

Considerando que os alunos do primeiro ano do curso de odontologia precisam ser motivados a aprender conceitos básicos para aplicações futuras, podemos concluir que existem uma motivação e interesse pela bioquímica que devem ser, na medida do possível, mantidos pelos professores responsáveis.

\section{REFERÊNCIAS}

[1] A.J. Formicola (1986) Preprofessional preparation for the basic science curriculum, J. Dent. Educ. 50, 458-461.

[2] R.M. Saunders (1996) The candidate of the future, J. Dent. Educ. 60, 411-415.

[3] C.M.D. Wannmacher (2001) Ensinando bioquímica para futuros médicos, Revista Brasileira de Ensino de Bioquímica e Biologia Molecular http://sbbq.iq.usp.br/revista/artigo.php?artigoid=1. 
[4] D.K. Yokaichiya, E. Galembeck, B.B. Torres (2001) Expectativas e fatores de interesse por ensino a distância na área de bioquímica: relatos de uma pesquisa pré e pós aplicação de uma disciplina de bioquímica à distância, Revista Brasileira de Ensino de Bioquímica e Biologia Molecular -

http://sbbq.iq.usp.br/revista/artigo.php?artigoid=38.

[5] J.R. Davies \& G. Warfvinge (2003) Basic biology integration - the Malmo model, (Abstract) Eur. J. Dent. Educ. 7, 94.

[6] B.J. Baum (2003) Can biomedical science be made relevant in dental education? A North American perspective, Eur. J. Dent. Educ. 7, 49-55.

[7] W.A. Welker (1992) The dental curriculum: is relevant to dental practice?, J. Prosthodont. 1, 47-50.

[8] B.J. Baum (1997) The absence of a culture of science in dental education, Eur. J. Dent. Educ. 1, 2-5.

[9] D.A. Nash (1998) 'And the band played on . . '', J. Dent. Educ. 62, 964-974.

[10] L.L. Dudlicek, E.A. Gettig, K.R. Etzel, T.C. Hart (2004) Status of Genetics Education in U.S. Dental Schools, J. Dent. Educ. 68, 809-818.

[11] R. Langer \& J.P. Vacanti (1993) Tissue engineering, Science 260, 920-926.

[12] M. Nakashima \& A.H. Reddi (2003) The application of bone morphogenetic proteins to dental tissue engineering, Nature Biotechinology. 21,1025-1032.

[13] J.A. Beeley (2003) Biomolecular sciences in the dental curriculum - broadening the base to increase the relevance, (Abstract) Eur. J. Dent. Educ. 7, 94.

[14] D. Kaigler \& D. Mooney (2001) Tissue Engineering's Impact on Dentistry, J. Dent. Educ. 65, 456-462.

[15] J.T. Wright \& T.C. Hart (2002) The Genome Projects: Implications for Dental Practice and Education, J. Dent. Educ. 66, 659-671. 